\title{
Built in refuge for the management of Pink Bollworm, Pectinophora gossypiella Saunders (Gelichidae: Lepidoptera) in Bt cotton
}

\author{
L. Rajesh Chowdary ${ }^{1 *}$, M. Bheemanna ${ }^{2}$, A.C. Hosamani ${ }^{2}$, A. Prabhuraj ${ }^{2}$, M. K. Naik ${ }^{3}$ and \\ J. M. Nidagundi ${ }^{4}$ \\ ${ }^{1}$ Main Agricultural Research Station, University of Agricultural Sciences, Raichur (Karnataka), INDIA \\ ${ }^{2}$ Department of Agricultural Entomology, University of Agricultural Sciences, Raichur (Karnataka), INDIA \\ ${ }^{3}$ Department of Plant Pathology, University of Agricultural Sciences, Raichur (Karnataka), INDIA \\ ${ }^{4}$ Department of Genetics and Plant Breeding, University of Agricultural Sciences, Raichur (Karnataka), INDIA \\ *Corresponding author. E-mail: chowdaryrajesh@ @otmail.com
}

Received: March 14, 2014; Revised received: April 20, 2014; Accepted: May 6, 2014

\begin{abstract}
Field experiment was conducted at the Main Agricultural Research Station, University of Agricultural Sciences, Raichur during 2012-13 to identify and evaluate the suitable refuge strategy systems for pink bollworm resistance management in Bt cotton (Gossypium hirsutum L.) cultivation. The experiment was laid out in randomized complete block design with nine refuge systems : $0 \% \mathrm{~N}-\mathrm{Bt}(\mathrm{BIR}), 5 \% \mathrm{~N}-\mathrm{Bt}(\mathrm{BIR}), 10 \% \mathrm{~N}-\mathrm{Bt}(\mathrm{BIR}), 15 \% \mathrm{~N}-\mathrm{Bt}$ (BIR), $20 \% \mathrm{~N}-\mathrm{Bt}$ perimeter refuge, $100 \%$ Non Bt, $50 \%$ Non Bt, $10 \%$ structured refuge and $20 \%$ structured refuge as treatments with three replications in replacement series. Significantly lowest incidence (3.55 larvae/plant) and number of bolls with exit holes (11.22) due to pink bollworm was recorded in $0 \%$ BIR $(41.25 \mathrm{q} / \mathrm{ha})$ followed by $5 \% \mathrm{~N}$ -Bt (BIR) with yield of $38.74 \mathrm{~g} /$ ha and this was on par with $10 \% \mathrm{~N}-\mathrm{Bt}(\mathrm{BIR})$ with yield of 37.79 is next best refuge systems with Bt cotton for higher production and greater economic benefits.
\end{abstract}

Keywords: BIR (Built in refuge), Cotton, Larval incidence, Pink bollworm, Structure refuge

\section{INTRODUCTION}

Extensive cultivation of $\mathrm{Bt}$ cotton (Gossypium hirsutum L.) can impose a continuous and intense selection pressure on bollworms of cotton leading to the latter's development of resistance to the toxin (Hardee et al., 2001). One of the conditions for environmental release of $\mathrm{Bt}$ cotton is that each such field is to be surrounded by a belt of non Bt cotton of the same variety to serve as "refuge" for bollworm. Refuge is any host plant (non Bt cotton, alternate host) that does not produce $\mathrm{Bt}$ toxin and has not been treated with conventional Bt formulations (Qiao et al., 2010). Refuge crops enable mating between resistant and susceptible adults, resulting in production of susceptible offspring (Kranthi et al., 2002; Kranthi and Kranthi, 2004). The refuge cropping strategy is designed to ensure that $\mathrm{Bt}$ susceptible insects will be available to mate with $\mathrm{Bt}$ resistant insects, should they arise. Available genetic data indicates that susceptibility is dominant over resistance. The off springs of these matings would most likely be $\mathrm{Bt}$ susceptible, thus mitigating the spread of resistance in the population (Hardee et al., 2001).

Early testing of transgenic Bt cotton included studies of seed blends offering a refuge for a resistancemanagement strategy. These blends contained a higher percentage of transgenic Bt cottonseed mixed with a smaller percentage of non-Bt cottonseed (Amy et al., 2001). By placing a blend of the two cottonseed types in the same bag, Monsanto could ensure that a refuge would be planted by growers with $\mathrm{Bt}$ and non-Bt plants interspersed in the same rows within a field known as refuge in bag or built in refuge. The development of an effective resistance-management plan for these insect-resistant cottons will provide growers with another tool in an integrated pest-management scheme for cotton. Therefore, the experiment was conducted to examine the effects of plantings of pure and blended genotypes of Bollgard $\mathrm{Bt}$ cotton and non-Bt cotton on the incidence of pink bollworm.

\section{MATERIALS AND METHODS}

The investigation was carried out at the Main Agricultural Research Station, University of Agricultural Sciences, Dharwad, Karnataka, India during 2004-05 and 2005-06. Bt cotton crop was grown as a rain fed crop with protective irrigation as on the stage of the crop. The climate of the study area is transitional in nature with bi-modal distribution of rainfall. The experiment was laid out in randomized complete block design with nine refuge systems : $0 \%$ $\mathrm{N}-\mathrm{Bt}$ (Built in Refugia), $5 \% \mathrm{~N}-\mathrm{Bt}$ (BIR), $10 \% \mathrm{~N}-\mathrm{Bt}$ (BIR), $15 \% \mathrm{~N}-\mathrm{Bt}$ (BIR), 20\% N-Bt perimeter refuge, 


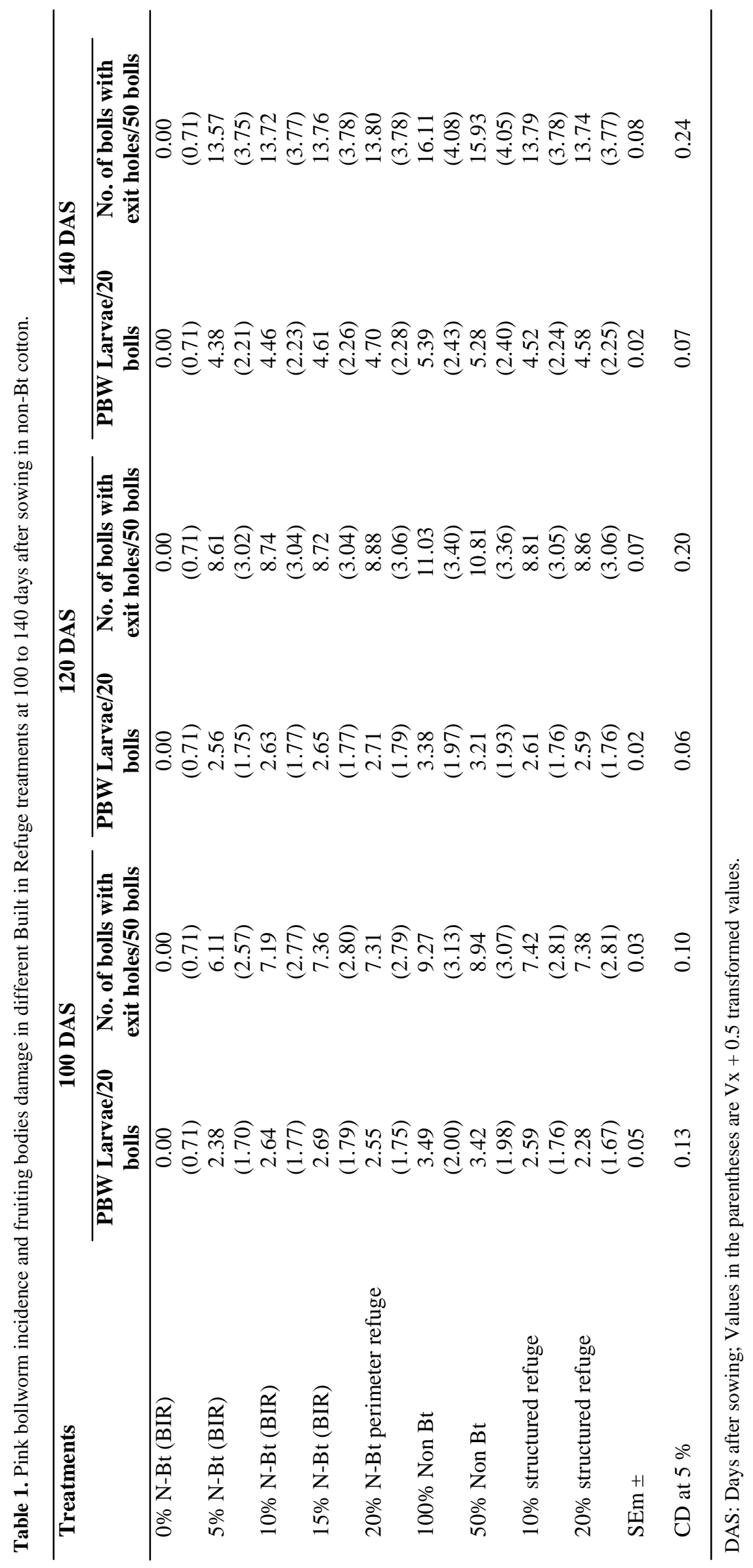


L. Rajesh Chowdary et al. / J. Appl. \& Nat. Sci. 6 (1): 202-206 (2014)

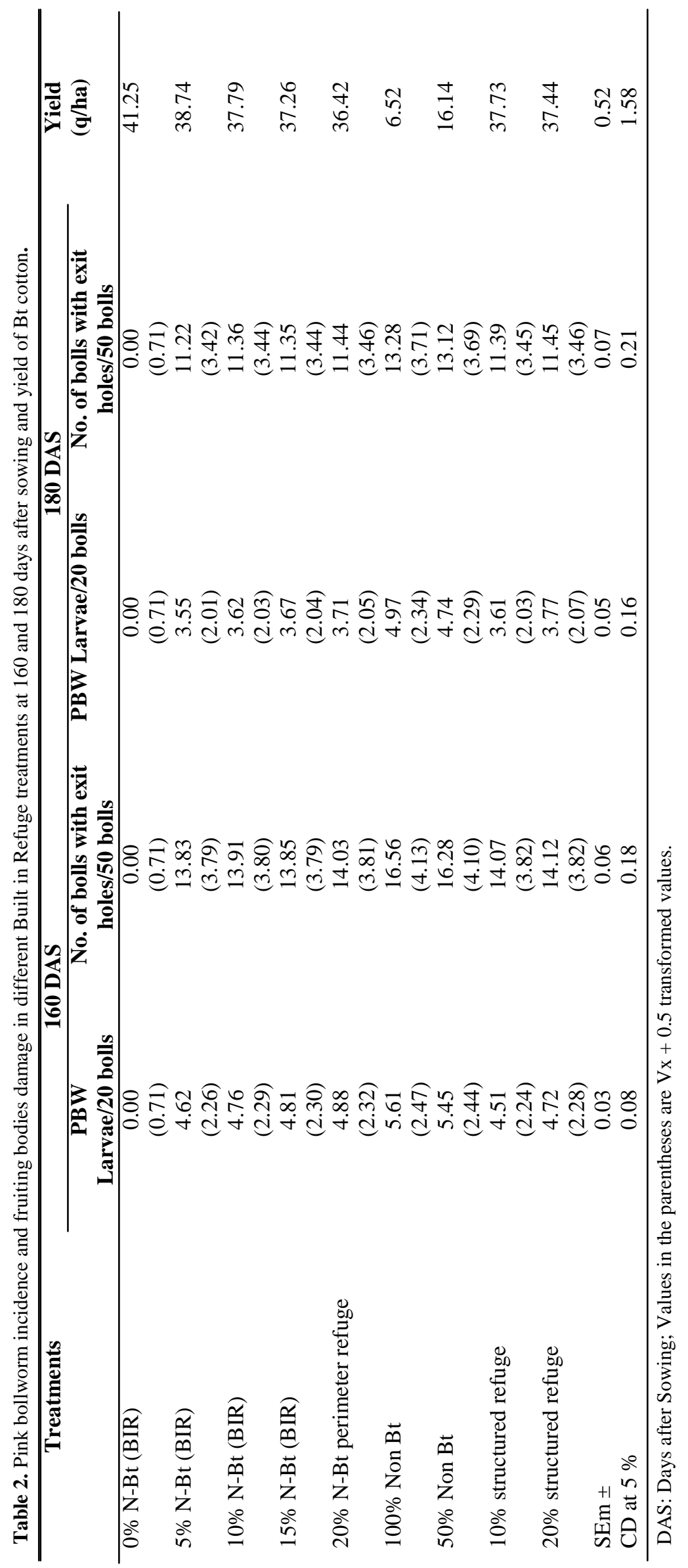


$100 \%$ Non Bt , 50\% Non Bt, $10 \%$ structured refuge and $20 \%$ structured refuge as treatments with three replications. The $\mathrm{Bt}$ cotton hybrid $\mathrm{RCH}$ BG-2 (Rasi seeds) was used in the study along with its respective non Bt cotton hybrid with a spacing of $90 \times 60 \mathrm{~cm}$.

The BIR treatments (5\% BIR, 10\% BIR and 15\% BIR) were planted in such a way that each Non Bt plant is surrounded by four Bt plants and observations in these treatments were recorded on the ten tagged plants and their surrounding four plants for each Bt plant. In the treatments of $10 \%$ structured refuge and $20 \%$ structured refuge the plants were selected randomly on ten Non Bt plants and forty Bt plants. Whereas in the treatment $20 \% \mathrm{~N}-\mathrm{Bt}$ perimeter refuge only plants surrounding the treatment plot was recorded and in $100 \%$ and $50 \%$ Non Bt fifty plants were randomly selected and observed. In all the refuge treatments the observation on pink bollworm incidence and number of bolls with exit holes were recorded by collecting green bolls at different time points starting from 100 days after sowing to 180 days after sowing. Finally yields were recorded in all the treatments and were statistically analyzed following standard methods using XLSTAT.

\section{RESULTS AND DISCUSSION}

In the present investigation, there was no incidence of pink bollworm in the sole Bt cotton without any seed mix of Non Bt at all the time points starting from 100 to 180 days after sowing. The incidence of larvae (2.38 larvae/plant) and number of bolls with exit holes (6.11) was lowest in the treatment 5\% BIR and it continued up to 180 days after sowing where in lowest incidence was noticed compared to all other treatments and was on par with rest of the refuge treatments at all the time points. $10 \%$ BIR recorded the larval population of 2.64 larvae per plant and 7.19 bolls with exit holes and was on par with $15 \%$ BIR and also other refuge treatments. At all the time points the pink bollworm incidence and number of bolls with exit holes was highest in the treatment of $100 \%$ Non Bt which was followed by $50 \%$ non $\mathrm{Bt}$ and dint differ significantly. At 180 days after sowing the larval incidence in the pure stature of Non Bt plot recorded 4.97 larvae per plant and with 13.28 bolls with exit holes out of fifty bolls (Tables 1 and 2).

With respect to seed cotton yield in different refuge strategies differed significantly. Among the different refuge treatments sole $\mathrm{Bt}$ cotton without Non $\mathrm{Bt}(0 \%$ $\mathrm{BIR})$ recorded highest yield $(41.25 \mathrm{q} / \mathrm{ha})$ and this treatment was followed by $5 \%$ BIR which recorded $38.74 \mathrm{q} / \mathrm{ha}$ which differed significantly. The treatment with $10 \%$ BIR recorded yield of 37.79 q/ha and was on par with $5 \%$ BIR. The treatment with $50 \%$ Non Bt recorded $16.14 \mathrm{q} / \mathrm{ha}$ and Lowest yield of $6.52 \mathrm{q} / \mathrm{ha}$ was noticed in the treatment with $100 \%$ Non Bt (Table 2). Not much significant differences were noticed in the treatments of $5 \% \mathrm{~N}-\mathrm{Bt}$ (BIR), $10 \% \mathrm{~N}-\mathrm{Bt}$ (BIR), $15 \%$
$\mathrm{N}-\mathrm{Bt}$ (BIR), $20 \% \mathrm{~N}-\mathrm{Bt}$ perimeter refuge, $10 \%$ structured refuge and $20 \%$ structured refuge with respect to larval incidence but with respect to yield all the refuge treatments differed statistically. Compare to existing refuge strategy $5 \%$ and $10 \%$ BIR recorded highest seed cotton yield and with respect to larval incidence these treatments were statistically on par with each other which implies that both the refuge treatments have same larval population and equal number of adults to mate with the resistance adults which emerge from Bt fields. Much of the concern surrounding the intrafield refuge, or mixed seed, strategy for resistance management is that seed mixtures may enhance resistance in mobile insects such as bollworm and tobacco budworm (Mallet and Porter, 1992). Seed blend efficacy trials by Durant (1995) also demonstrated that yields in seed treatments containing $100 \% \mathrm{Bt}$ seed were significantly higher than some seed treatments containing mixtures of $\mathrm{Bt}$ and non-Bt seed. Durant (1995) concluded that seed mixes containing less than $90 \% \mathrm{Bt}$ seed may not provide acceptable control of bollworm and tobacco budworm. The $0 \%$ Bt:100\% non-Bt plots had significantly higher larval numbers and damaged fruit and significantly lower yields than all other seed treatments both years. Amy et al. (2001) revealed that the treatment containing $100 \% \mathrm{Bt}$ seed had lower percent larval infestation and percent damaged fruit and higher yields than all other seed blends in both years. In general, mean percent larval infestation and mean percent damaged fruit increased in both years as the percentage of $\mathrm{Bt}$ seed in the blends decreased. Conversely, seed cotton yields decreased as the percentage of $\mathrm{Bt}$ seed in the blends decreased. Pink bollworm, Spotted bollworm and Spiny bollworm and, therefore, it becomes necessary to provide them with adequate cotton (non-Bt) crop itself as refuge to support the required susceptible populations. The later-instar larvae of Pectinophora and Earias hardly move between plants. So, the question of their moving from non-Bt to $\mathrm{Bt}$ plants is hardly a concern (Manjunath, 2012).

\section{Conclusion}

The present study concluded that of these different refuge treatment strategies tested, $5 \%$ or $10 \%$ built in refuge were considered as an effective refuge seed mix in delaying the resistance build-up in pink bollworm. Transgenic Bt cotton provided an effective and more environmentally sound means of controlling cotton lepidopteran insect pests. Further research is necessary to determine the most practical refuge options and to quantify amounts of refuge necessary to delay resistance to transgenic Bt cotton in bollworms.

\section{REFERENCES}

Amy, L., Agi, Jay, S., Mahaffey, J. R., Bradley, Jr. and John Van Duyn, W. (2001). Efficacy of seed mixes of 
transgenic $\mathrm{Bt}$ and non transgenic cotton against Bollworm, Helicoverpa zea Boddie. The Journal of Cotton Science, 5:74-80.

Durant, J. A. (1995). Efficacy of selected seed mixes of transgenic $\mathrm{Bt}$ and nontransgenic cotton against bollworms and tobacco budworms in South Carolina. pp. 769-771. In Proc. Beltwide cotton conf., San Antonio, TX. 4-7 Jan. 1995. Natl. Cotton Counc. Am, Memphis, TN.

Hardee, D.D., Van Duyn, J.W., Layton, M.B. and Bagwell, R.D. (2001). Bt cotton, continued effectiveness by managing resistance of tobacco budworm and bollworm. USDA-ARS-154. USDA-ARS, Stoneville, MS.

Kranthi, K.R. and Kranthi, N.R. (2004). Modelling adaptability of cotton bollworm, Helicoverpa armigera
(Hubner) to Bt-cotton in India. Current Sci., 87(8): 1096-1107.

Kranthi, K. R., Jadhav, D. R., Kranthi, S., Wanjari, R. R., Ali, S. and Russell, D. (2002). Insecticide resistance in five major insect pests of cotton in India. Crop Protection, 21: 449-460.

Mallet, J. and Porter, P. (1992). Preventing insect adaptation to insect-resistant crops: Are seed mixtures or refugia the best strategy? Proc. R. Soc. Lond., 250:165-169.

Manjunath, T. M. (2012). Bt-cotton: refuge in seed-mix some clarifications on its need and viability. Current Sci., 102 (4): 541-542.

Qiao, F.; Huang, J., Rozelle, S. and Wilen, J. (2010). Natural refuge crops, buildup of resistance, and zero-refuge strategy for Bt cotton in China. Sci. China Life Sci., 53:1227-1238. 